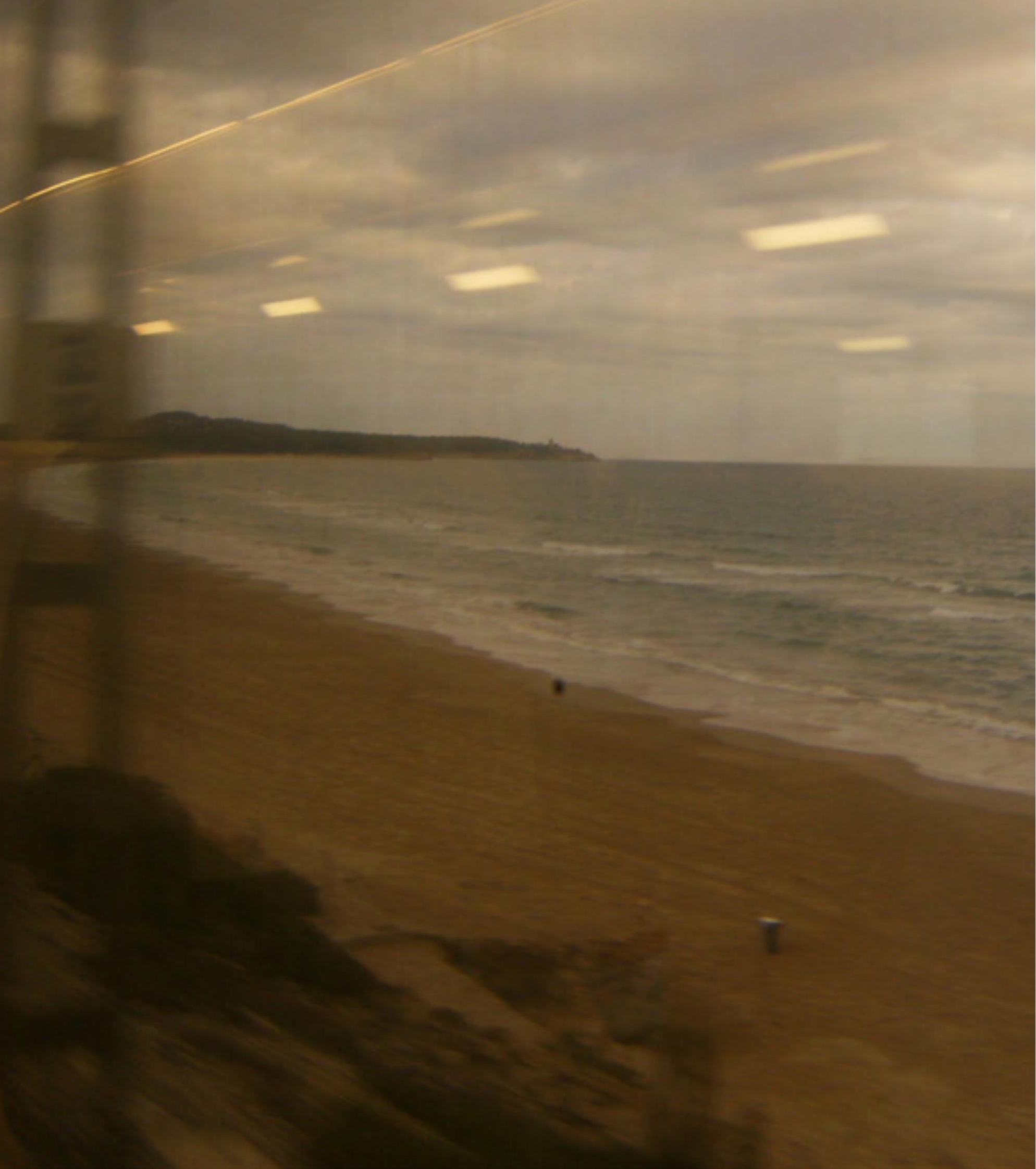




\title{
O viajante e o sentimento oceânico
}

The traveler and oceanic sense

\author{
Eduardo Yázigi ${ }^{1}$
}

1 Professor Titular do Departamento de Geografia da USP. Email: edyaz@usp.br 


\section{Resumo}

Esta abordagem procura diferenciar o viajante dos turistas comuns de nossos dias. Esses últimos seguem as publicidades sedutoras dos tours operators, as quais, por todas as partes, anunciam o mesmo padrão de atrativos: os espetáculos imperdíveis, a arquitetura monumental ou patrimonial, as boas compras, as feiras temáticas comerciais, as grandes festas etc. Convencionemos chamar este menu como atrativos de superfície. Descendo aos subterrâneos das civilizações, o viajante busca antes o caminho das profundezas culturais que apesar dos tempos ainda subsistem, a paisagem para ser vivida e não vista, a cultura e arquitetura vernacular, as tradições ameaçadas pelos projetos do que deve ser o "in". Mochileiros, por exemplo, em geral dotados de espírito aventureiro e dispondo de menos recursos carregam seus hotéis de lona e o instalam nos lugares iluminados ou temperados com as lides simples dos povos esquecidos, com suas artes fora de moda, mas ricas do sentimento da coesão social. O mochileiro, ao contrário dos turistas, precisa de mais tempo, porque soa ridículo a atitude normal do turista comum que leva dois minutos contemplando a Mona Lisa e ficam mais de horas vasculhando as butiques do Museus. A primeira ou segunda opção depende de escolha que o homem faz para si mesmo, os valores que deseja cultura e aprender. Mas não se trata de julgar o turismo comum, desgraçadamente limitado pelo tempo e interesse, de uma viajante que seria mais sábio. Ambas as coisas podem coexistir porque a priori não realizamos uma única viagem na vida e só a experiência dirá o que vale a pena. Mas é preciso experimentar para dar o parecer final. O sentimento oceâncio não pode ser encontrado em todas as partes.

Palavras-chave: turismo, viajante, sentimento oceânico

\section{Abstract}

This approach looks to differentiate travelers and the actual tourists. These last mentioned follow seductress publicities given by tours operators - those that every where announce the same pattern of attractives: show business; monumental architecture; historic patrimony; good shopping; thematic exhibitions; big parties, etc. Let's agree that this way is a superficial menu. Going down to the deep of civilizations, the traveler seeks before all the ways to reach the cultures depths that after all survive; exceptional landscapes to be lived and not only to be seen; vernacular and cultures and architectures, traditions threatened by "in" projects. Backpackers are commonly different from tourists. They need more time because normal tourists sound ridiculous: they spend two or three minutes regarding Mona Lisa and then 30 or 60 minutes at the Museums shop. The travelers options depends of the choice made to their selves, the values and cultures they wish to learn. But here we do not want to crucify the common tourist, whose time and interests are limited - different from travelers. Both ways can exist because during the life we do not make only one travel, but only the difference between one and other can tell us the gain. But we must try both of them to give the final options. Oceanic feeling cannot exist everywhere!

Key words: tourism, traveler, oceanic sense. 


\section{INTRODUÇÃO}

\section{Cronos e Kairos: dois entendimentos diferentes de tempo}

Como muitos devem saber, os gregos possuíam dois entendimentos na consideração o tempo: o kronos, essa medida linear de minutos, horas, dias, etc. e o Kairós, por eles considerado como o tempo oportuno e que Igreja considera o tempo de Deus porque uma série de conjunções define uma complexa situação que não pode ser produto do acaso. De fato a história registra coincidências, que de acordo com Arthur Koestler, tem se registrado como sendo até de 6․ grau - uma situação muitíssimo rara que pode bascular nossas vidas.

Na seqüência, um exemplo ilustrativo do que seja uma conjuntura propícia a certo sucesso, mas tenha-se em mente que se trata de uma conjuntura calculada e não espontânea como no caso do Kairós. Imaginemos uma viagem a Júpiter. De pronto se impõe duas pré-condições: a viagem deverá ser a mais curta possível porque o combustível é sempre limitado e ainda porque o incômodo à bordo extenua um ser humano. Logo, tal viagem deve se efetuar quando o planeta estiver mais perto da Terra. Se dispusermos de um foguete para alcançar Júpiter, seria inútil mirá-lo e lançá-lo no exato momento em que ele está visível: a viagem se torna inútil em virtude de Júpiter estar rodando o sol, com velocidade determinada. Para que este planeta seja alcançado, seria necessário dispor de um cálculo exato que considere seu movimento de rotação em torno do Sol, o movimento da Terra, a velocidade do foguete e o tempo que ele efetivamente levaria até atingir seu objetivo o planeta Júpiter na menor distância. Seria necessário considerar os dados precisos do planeta: sua velocidade e o exato momento em que ele seria atingido pelo foguete terrestre que tem seu tempo para chegar pela menor distância. Esta oportunidade é o que os engenheiros espaciais chamam de "janela", isto é o momento absolutamente preciso lançar o foguete para atingir seu objetivo. Considere-se também Que nossa própria constelação está em movimento assim como a nossa própria galáxia. Logo, precisamos contar com todos esses cálculos complexos e $100 \%$ seguros. Isto é, definir uma conjuntura cósmica planejada para dar certo, onde o tempo, os movimentos e as distâncias são fatores indispensáveis para o sucesso. Isso foi exemplificado para que se entenda o Kairós, mas que não pode ser calculado por nós e que por esta razão é denominado pela Igreja como sendo o Tempo de Deus, porque se torna uma oportunidade de modificarmos a disposição de tudo, sem nossa interferência.

É minha hipótese que Kairós, o sentimento oceânico, a síndrome de Stendhal a serem explicados mais à frente e a consciência cósmica da meditação védica são situações muito similares que podem nos alterar substancialmente e nos causa a 
sensação de sermos uma totalidade com o universo. Significa também que nossa mente se abre para estabelecer comunhão com a parte visitada pelo viajante. Isso é coisa de viajantes, turistas não são a mesma coisa!

\section{PRIMÍCIAS DAS VIAGENS}

É a própria Pré História e a História que nos evidenciam: viagens são fatos universais, demonstrando (pelo que se sabe) se iniciam no habitat que de uma fóssil denominada Lucy: um movimento de expansão pela norte da África, Europa, Ásia, Oceania e Américas por diversas razões: contendas, esgotamento das reservas alimentícias de coleta, etc.. Bem mais tarde, como a revolução agrícola estabeleceu a fixação habitacional estável num determinado território, fundaram-se as primeiras agrovilas e cidades.

$\mathrm{Na}$ África, nos vários Orientes e na Europa fundaram-se as mais velhas cidades do Mundo, a evolução se dando de modo específico em cada lugar. De fato, a mudança é inata ao homem, devido a vários progressos: escrita, conhecimento enriquecido, tecnologia, questões climáticas, etc. Neste sentido, Martin Heidegger (1889-1976) com sua obra Sein und Zeit - o Ser e o Tempo - e Aristóteles insistem: tudo o que existe tem uma forma, mas o Ser se modifica com tempo e conseqüentemente sua forma original se torna bem outra. Heron de Alexandria já havia inventado o protótipo da máquina a vapor (um brinquedo de crianças) no século II D.C. e, conquanto pudesse aperfeiçoar facilmente sua criação, não chegou a provocar a Revolução Industrial acontecida no século XVIII na Inglaterra: a posse de escravos egípcios dispensava a máquina.

Marco Polo de Veneza (1254-1324) e Ibn Batuta (1304-1377) de Tanger contam-se entre os principais viajantes que deixaram registros de diversas naturezas do que encontraram em suas longuíssimas viagens, às vezes de narrativa mítica, enquanto a viagem da Rainha de Sabá, ao sair da Etiópia para visitar o Rei David, se reduziu a poucas menções de trajeto no Antigo Testamento.

O importante de se reter sobre o Ser e o Tempo é que tudo se modifica e que a procura do viajante de hoje, desejoso de conhecer e vivenciar o profundo de qualquer civilização, dificilmente encontrará formas tradicionais antigas, porque elas já passaram por transformações. A primeira pergunta que advém desse fato é: qual profundidade procuramos, de qual tempo, e aonde são encontrados? Quem quiser conhecer o que fossem tradições egípcias, gregas, chinesas ou incas, terá de recorrer à documentação disponível e não a grupos que rarissimamente se mantêm: somos 
todos afetados pelo impacto tecnológico, além da evolução cultural, dos climas, etc.

Em decorrência dessas circunstâncias que tratam dos valores profundos dos grupos sociais, ocasião em que a busca de uma experiência turística pergunta é: onde achá-los? Como o moderno é o melhor modo de como o passado chegou até nós, só existem duas opções: recorrer à documentação histórica (que inclui materialidades) e o vivencial que pode permanecer variadamente enraizado, malgrado os constantes progressos científicos do tempo. Trata-se então de uma fina garimpagem à procura de fenômenos humanos de qualquer natureza que permanecem como práticas aqui e a acolá, concorrendo com a modernidade global, mas com diferentes nuances entre os povos.

Cabe ao viajante descobrir o sentido do profundo de acordo com seus objetivos, revelando práticas e crenças alternativas que apesar de antigas se conservam malgrado a vida moderna: formas de organização familiar, social, técnicas, concepção do eterno, medicinas, etc. Tais grupos vernaculares foram e continuam a ser estudados pela etnografia, mas como também vão se modificando segundo ritmos diferentes, a viagem pode contemplar soluções mais eficazes, das quais podemos sair de alguma forma positivamente diferentes quanto aos nossos valores. Ou até com decepcionados! Assim, como o dito chinês afirma que jamais conseguiremos nos banhar duas vezes no mesmo rio, a mutação mundial avança cada vez mais: não podemos dizer conheço muito bem Paris ou Nova York porque já não são a mesma coisa do que vi há vinte anos.

\section{NÃO À BANALIDADE}

Em seu livro pouco conhecido Les Bellles Images, editado em 1966, Simone de Beauvoir critica a burguesia feminina dos anos!960, citando certas madames para quem, jocosamente, o Tahiti: "C'est d'un banal" porque teria virado coisa de "français moyen". Foi nesses anos que as grandes viagens aéreas se tornaram mais fáceis, enquanto os navios declinavam suas travessias transoceânicas. Esta simples reflexão de Beauvoir não é exclusiva das mulheres, mas ao mesmo tempo nos conduz à uma reflexão sobre a profundidade. Não se trata de fazer apologia de que no passado tudo era mais bonito, pacífico e melhor, e sim refletir sobre a importância das tradições exemplares que permanecem. $\mathrm{O}$ que aconteceu com as tradições pelo mundo afora? Que proveito podemos dela tirar se uma viagem é também um aprendizado?

Quem já nasceu no tempo das baladas com seus ritmos frenéticos, Smartphones e badalações do momento, acha isso tudo o que há de melhor no mundo. Sea, Sun 
and Sex é um trilogia que continua mais fortes do que nunca porque não abrimos mão do sexo. Executivos em viagens bem curtas já partem com ingressos comprados e vão usufruir o The Best of the best mais recente.

Entrementes vem surgindo aos poucos uma categoria de autores de crítica virtualmente jocosa como Enrique Rojas, médico psiquiatra em El Hombre light. Uma vida sin valores. O que terá sobrado de pequenos grupos étnicos e dos cidadão que começam a descobrir o país profundo, cuja serventia será demonstrada mais adiante? Já Gilles Lipovetsky aborda muito a falta de ética em nossos tempos e o imenso vazio que domina o homem moderno.

\section{CRISES E MIGRAÇÕES}

Hoje vivemos a já referida era técnico-científica-informacional. Assistimos a acelerados progressos que melhoram nossas vidas, como na Medicina, por exemplo - ainda que seus avanços estejam a distâncias abissais das populações pobres e de eficácia sem contra indicações. Mas a exploração dos laboratórios farmacêuticos com sua profanação da raça humana constitui uma das maiores vergonhas da ciência. A globalização, por " $n$ " razões estimulou imigrações de povos que vivem sob atroz penúria, em direção do mundo desenvolvido, que por sua vez se sobrecarrega de crises, limitações monetárias, etc. Mesmo assim há populações pobres que lograram atravessar para este mundo dito melhor para conseguir emprego ou então serem banidos: assistimos a grandes êxodos clandestinos que têm custado a vida de centenas de milhares de humanos em suas perigosas travessias marítimas. Ainda está para ser escrito um Tratado Geral desses êxodos forçados pela ditadura dos países de origem. Mas vale registrar um fato que jamais vi comentado: A Europa - Inglaterra, Bélgica, Franca, Portugal, Espanha, Alemanha, Itália, dentre os principais, exauriram as riquezas e as vidas humanas da maior parte dos países habitados tradicionalmente e detentores de riquezas minerais ou artísticas que Ihe foram vergonhosamente roubadas, sobretudo a partir do século XIX: Toda a África do Norte, o Congo Belga (que era propriedade particular do Rei que matou dez milhões de congoleses!). O "heróico" Napoleão (para os franceses) não deixou de ser um general sanguinário, como um assaltante do Egito. A expropriação ocorreu igualmente no Oriente Médio, na Índia, Extremo Oriente e ilhas do Pacífico, Atlântico e Indico. Ora, sob uma conjuntura mundial nefasta, a maioria desses povos subdesenvolvidos procura um lugar ao sol para viver, mas chegam a ser tratados com cães empesteados. A Europa não quer receber o troco de suas monstruosidades, sob cínico auto-panegírico de civilizados. Considere-se então o que sobrou de profundo nas terras amaldiçoadas. 
A Europa tem sido um dos alvos preferidos dos imigrantes. Países que foram colonizados a ferro e fogo acabam por procurar o antigo dominador infame, grandemente devido ao domínio de sua língua. Agora esses não querem receber o troco dos antigos colonizados que, "sem educação ou higiene espalham a peste" em suas castas terras. Sejamos claros: a Europa inventou o conceito de civilização a fim de praticar o racismo mais imundo da face da terra

A frase mais banal da França hoje em dia é: "On n'est plus chez-nous": "já não estamos mais em nossa casa" - por causa dessas hordas imundas que não param de chegar clandestinamente. Perdem de vista os incontáveis equívocos por eles mesmos praticados no campo da tecnologia e da educação a partir da Convenção de Bologna que nivelou a Europa inteira de superficialidades, tão lucidamente explicadas pelo Professor espanhol José Carlos Bermejo Barrera em sua obra La Consagración de la Mentira. Nessa linha de pensamento, o livro The last days of Europe do autor Laqueur explica que a Europa não terminou, mas se tornou outra coisa, muito modificada. Há um jargão comumente ouvido nos ambientes de que "o mundo ficou todo igual". Ficou é? Será mesmo que não existem mais lugares profundos que resistem heroicamente, até nos seio das grandes metrópoles? E grupos que vêem a globalização de modo diferente?

Metrópoles, por serem grandes e alvo de imigrações, acabam por abrigar grupos étnicos - se é que ainda se pode falar em etnias - que sobrevivem, mas na condição de hóspedes fiéis às suas religiões. Sim, vivem à sua maneira tanto quanto podem e o Islamismo é um forte exemplo hoje encontrado por todas as partes, ainda que bem ou mal acatando as normas do país receptor.

Nesta brevíssima introdução não podemos ignorar o papel dos tour operators e seus ditames do que é indispensável de ser visto. A Internet está repleta de "pacotes" sedutores do lugar comum. As grandes vedetes, com suas viagens sobejamente anunciadas pelas revistas light são outros formadores de opinião. Basta lembrar que Brigitte Bardot é responsável por um dos destinos mais procurados pelos brasileiros: Búzios, e inclusive Saint Tropez. Quando Fernando Collor de Mello resolveu desfrutar das águas oceânicas de Seychelles, uma onda de "bem nascidos" brasileiros quiseram repetir a façanha, antes mesmo de saber onde fica tal ilha...

\section{O TURISTA DA MODERNIDADE VERSUS VIAJANTES}

Cada turista costuma repetir o mesmo padrão de escolha: crianças nunca se esgotam com Orlando ou Euro Disney. Sedutoras donzelas costumam preferir praias onde mostrar seus dotes bronzeados. Empresários são fãs assíduos de feiras temá- 
ticas e congressos de sua especialização, nas horas vagas costumam prolongar o tempo para alguma gandaia ou um show da Broadway. É o império da banalidade de certo padrão de gosto...

Subsiste uma plêiade de seres espalhados pelo mundo, insatisfeitos com a vida que levam. Por fuga, curiosidade, filosofia de vida ou outra coisa anseiam pelo encontro de autenticidades válidas que conseguem sobreviver segundo certas formas de organização social e de vizinhança. Mas quando pensamos em tradições, não quer dizer quanto mais velhas melhor porque a dinâmica geral do mundo é sempre e sempre modificada pelo momento: algumas podem ter subsistido aos tempos de Cristo ou do Reinado de D. Pedro II. Os grandes folcloristas como Rossini Tavares de Lima, Mário de Andrade, Inezita Barroso, Oneyda Alvarenga (1911-1984), Kilza Setti, ou ainda recônditos heróis fiéis que viveram experiências que quase se apagavam, nos reiniciam num mundo mais humano na medida em que resolvem modos de vida, na condição de ainda existir um ou mais líderes que são a memória viva dos costumes. Os grandes estudiosos dos caipiras como Antônio Cândido, Nice Lecoq Muller, Darcy Ribeiro, Maria Isaura de Queiroz, Aziz Ab'Saber, Monteiro Lobato e muitos outros nos evidenciam que o verdadeiro caipira ou caiçara não existe mais, ainda que assim se declarem: as últimas gerações começaram desaparecer a partir de 1948 quando o Brasil entrou na comercialização internacional da carne e invadiu as terras devolutas desses antigos grupos. E o que falar do incomensurável conhecimento das civilizações indígenas de todas as Américas? Hoje, laboratórios químicos se servem do conhecimento desses nativos para fórmulas médicas ou cosméticas, embora ainda não tenham conseguido explorar todo o conhecimento que desaparece com a morte dos último mohicanos.

Mochileiros na cidade grande chegam a ser irritantes quando entopem o espaço de multidões, ônibus ou metrô. Em contraposição são os mais autênticos caçadores das profundezas da civilização, mas aí já caminham com mochilas bem maiores porque levam consigo tudo o que precisam para habitar qualquer lugar, a começar pela tenda. Não obstante o mundo profundo não é privilégio só seu e sim de qualquer cidadão, de qualquer idade movido por várias razões: desde o saudosismo até a redescoberta de outras formas de viver. Acho muito curioso como os intelectuais se referem ao saudosismo com arrogância pejorativa. A saudade pode ocorrer com qualquer um e me parece muito estranho que um povo chega a mentir dizendo que esta palavra é exclusivo do português e, no entanto a negue em casos em que é ela indispensável, ou mesmo um lenitivo.

A dificuldade de procura pelo profundo se acha supostamente presente nas co- 
munidades recônditas e isoladas, mas para espanto nosso são encontradas nas grandes metrópoles: os pequenos grupos da grande urbe são integrantes do cosmopolitismo. Quer dizer, chegam levas que logo se integram aos estilos de vida dominantes, como outros que se agregam para se proteger e conviver na doce lembrança e segurança do que trouxeram consigo. São Paulo é um exemplo de comunidades sírias, italianas, bolivianas, nordestinas, gaúchas ou coreanas que ainda conservam costumes, por mais modernos que sejam seus modos de vida. Mas também e isto é mais sugestivo ainda, facções de diversas partes do Brasil são encontradas em São Paulo. Não somente da mesma origem geográfica, como também corporativas. Os CTGs - Centros de Tradição Gaúcha - que se espalham pelo mundo todo constituem um dos melhores exemplos de autenticidade.

Quantos paulistanos sabem da existência de certos grupos tradicionais (que podem ou não ter celulares e outras modernidades) que costumam repetir os cantos do passado que sobreviveram até o presente? Na lateral interna do Pátio do Colégio, um grupo etário de 70 a 80 anos se reúne todas as terças-feiras pela tarde para fins de bate papo, troca de discos 78, LP, ou CDs, além de fazer exibições relâmpago de fotos da São Paulo, e das estrelas dos anos 1940. Autodenominam-se Gletianos porque estudaram na Faculdade de Filosofia da USP, no em tempo que ela funcionava num casarão da Alameda Glete. Derrubaram o casarão, mas não a grande árvore do jardim sob a qual iam fumar ou namorar nos intervalos. Com medo de que a árvore fosse também a baixo, clonaram mudas da mesma no campus da USP! $\mathrm{Na}$ "Casa Contemporânea", numa feia rua travessa da Rua Santa Ifigênia, todos os sábados, das 10 às 15 horas acontecem matinês do mais autêntico chorinho, grátis, executado por anciões cujo público e feito de jovens querendo aprender ou apreciar o que seja este ritmo tão pouco comercial. Agora se chama Rua do Choro. $\mathrm{Na}$ Rue de Seine Paris, talvez ainda exista a gráfica de Raymond Duncan, irmão de Isadora Duncan (1877-1922), a grande bailarina americana que revolucionou o mundo com a dança moderna. Faleceu estrangulada quando, dirigia um conversível na Côte d'Azur: sua longa echarpe de seda se enganchara na roda do auto. Um grupo de fiéis admiradores freqüenta a velha gráfica de Raymond, dotada de pequeno salão de palestras. O Instituo Rachmaninov da mesma cidade oferecia um almoço de bom preço para imigrantes russos escapados da Revolução de 1917... E assim, se repetem fórmulas pela Itália, países Escandinavos, Eslavos, Latinos Americanos, Árabes, Persas, sem falar da imensa África. A Itália se deu ao luxo de inventar a Cuccina lenta cuja comida leva mais de hora para ser preparada, como antigamente. Daí partiram para a concepção das cittás lente, hoje com grande número de representações no mundo, que por sua vez inspirou o new urbanism. O Brasil tenta em vão alinhar Pra- 
do e Tiradentes nessa condição, mas as auditorias só autorizam engajamentos que transcendem o poder político E qual político municipal consegue garantir normas patrimoniais ao longo do tempo, mediante severo controle? O Brasil sempre voa atrás do que dá certo, mas é incapaz de cumprir a tarefa, que passa a ser relegada.

Muitas vezes surge um turista, ou crítico que assistindo a uma performance musical, de dança ou ritual religioso, tacha-os de falsos. Assim ignoram várias coisas com essa difamação inconseqüente. 1) Povos primitivos têm o direito de usar microfones, gravadores ou blue jeans; 2) Jamais suas apresentações podem ser consideradas falsas, na medida em que se anunciam como cultivadores de um ritual passado: não estão mentindo; 3) Não podem ser acusados de mercenários se cobram entrada para uma apresentação se vivem disso. Quer dizer então que professores ou outra profissão podem cobrar pelas aulas dadas e os pobres não? 4) Esses críticos verborrágicos que qualificam o espetáculo ou ritual de falso, são simplesmente negligentes, porque jamais se deram ao trabalho de estudar o que seja o complexíssimo conceito da verdade antes de acusar isto e aquilo de falso; finalmente, 5) A tradição, mesmo inventada no ano passado, possui um sentido extremamente importante para a sociedade porque serve para manter a coesão do grupo social, conforme tão bem defendeu Eric Hobsbawn.

Agora duas palavras sobre o papel da fantasia tão comum no turismo, como se fosse uma apelação a ser exorcizada para ficar só com a realidade nua e crua. Totalmente errado! Segundo Freud, a fantasia cumpre dois papéis sem o qual não conseguimos sobreviver com sentido: ela serve para atenuar as neuroses e, sobretudo ajuda a criar modelos de futuro que guiarão nossa vida. Trata-se apenas de ter consciência de estar manipulando fantasias e não estar vivendo uma esquizofrenia.

\section{AS GRANDES NAVEGAÇÕES DO SÉCULO XIX}

Historicamente a cartografia do mundo se completou no século XIX, grandemente facilitada por vários instrumentos de verificação e documentação pictórica \& fotográfica. No entanto, demarcar o contorno das terras era ainda muito pouco. Passou-se então a explorar as sociedades que habitavam cada lugar e como viviam. Darwin, Von Humboldt são responsáveis por grandes descobertas e teorias científicas, assim como, já antes, uma plêiade de cientistas e artistas, deixaram telas excepcionais, como Debret ou Frans Hals. Dezenas de viajantes famosos com seus diários, como Saint Hilaire correram o território brasileiro anotando tudo o que experimentavam. No Brasil, o Marechal Rondon e os irmãos Vila Boas foram grandes humanistas e documentaristas já no século XX. No início da nascente antropologia, 
esta se referia a tudo que não fosse europeu com nojo a fim de afirmar sua colonização "superior": só o Rei da Bélgica, que tinha o Congo como sua propriedade particular, mandou matar dez milhões de nativos. Um gesto comum e aceitável para as elites européias... O nascimento do Relativismo Cultural apontou para descrições que se limitavam à descrição do que viam e julgavam, não hesitando em qualificar negros ou índios brasileiros de antropófagos. Logo o equívoco se tornou patente, isto é, não deviam mais ser juízes dos valores, e sim analistas descritivos como Ruth Benedict se tornou um bom exemplo com seu Paterns of Culture.

\section{A IMPORTÂNCIA DAS CIÊNCIAS HUMANAS}

Os guias impressos no Brasil são exímios em dois assuntos preponderantes e limitativos: explorar Cama e Mesa ad nauseam. Festinhas locais ou outras coisas interessante de ser ver são meros apêndices curtos do guia 4 Rodas. Já os Guias Michelin, sem dúvida entre os melhores do mundo, são imbatíveis nas informações sobre a cultura, que não raro incluem até plantas de igrejas ou castelos. Felizmente estão chegando ao Brasil. $O$ drama nosso é que liquidamos com a maior parte de nossa cultura de raiz, sendo necessário cavocar muito para se achar o que há de apreciável.

Por suas variadas naturezas, história e geografia, assim como etnografia e outras disciplinas humanísticas são fontes de primeira grandeza para nos preparar à visão turística. Mas infelizmente a linguagem muitas vezes hermética não é feita para o povo refletir, e assim nos contradizemos quando alegamos que o povo não lê e não entende nada.

A modernidade também deve ser aproveitada, mas com uma boa peneirada. A imersão no profundo não impede de aproveitar as beatitudes que nos salvam.

\section{UMA OPÇÃO DE VIAGEM}

Certa vez o ator Vitório Gassman, em entrevista com Roberto D’Ávila afirmou que devíamos ter duas vidas: uma para aprender outra para viver de verdade. Como isso é uma utopia, temos de reaprender tudo numa vida só. O conhecimento de longuíssima experiência urbana constitui um universo de opções. Se os autores se dessem ao trabalho de escrever mais fácil, ou a simples descrição de certo lugar, isso nos permitiria sair um pouco deferentes, ou mesmo basculados com a experiência visitada. A viagem terá valido a pena: o olhar no profundo transforma nossas vidas porque o verdadeiro presente é o modo como o passado chegou até nós. 
Entretanto a vida moderna nos impõe tempos curtos, forçando-nos a vivenciar as apoteoses. Mas existe uma saída proveitosa: sem sacrificar o senso comum do turismo, devemos eleger uma única região compativel com nosso interesse e a ela consagrar a maior parte do tempo, incluindo revisitas e arredores se necessário for.

\section{O SENTIMENTO OCEÂNICO: A COMPENSAÇÃO DO VIAJANTE}

Este conceito foi inicialmente concebido pelo prêmio Nobel na Literatura de 1915 Romain Rolland (1866-1944) no livro Futuro de uma ilusão (1927) e criticado por Freud em Les malaises de la civilisation. A compensação de certos tipos de viagem pode ser de ordem psicológica ou mesmo espiritual, na qual se tem a impressão de formar uma unidade com o universo, uma força maior do que nós mesmos. A exploração do conceito não é uma invenção deste autor, posto que, mesmo sem formulação adjetivada de tal sentimento já fora experimenta do por várias pessoas, durante viagens ou alguns tipos de encontros. Conquanto Freud rebata este sentimento no citado livro, a prova verídica é que tal fenômeno tem sido verificado assiduamente em " $n$ " indivíduos e em circunstâncias especiais, que tanto pode ser a visão de uma paisagem ou uma audição, canto gregoriano ou dança clássica e até moderna. Trata-se nada mais, nada menos que uma espécie de união com a eternidade, em oposição à banalidade frugal do tempo. As religiões creio que quase todas elas, têm fé na necessidade de procura do eterno.

Por exemplo, a meditação védica, conhecida há milhares de anos, difundida por Maharishi e por força constante de repetição de determinado mantra conduz ao que a Meditação Transcendental denomina "consciência cósmica", isto é, um estado alterado da consciência cientificamente comprovado e considerado benéfico: esta meditação age diretamente no sistema nervoso central e nada tem à ver com religião, é uma simples técnica específica, e não só dos vedas. Indígenas brasileiro e negros tribais de África entoam ritmos e cantos monossílabos que lhes permite entrar em transe. Até mesmo o Candomblé confirma que o transe é uma procura do sentido da vida.

Algo semelhante ao sentimento oceânico tem acontecido em alguns lugares como na Galeria Del Uficci, em Firenze. A Dra. Magherini, de um hospital local tem recebido muitos pacientes com taquicardia e outras perturbações devidas a simples contemplação da beleza existente nesta Galeria. Mas os pacientes se recuperavam no mesmo dia com um especial sentimento de transformação interior. Como Stendhal em Voyage em Italie, experimentara a mesma sensação diante da beleza, pude entender algo que acontecera comigo mesmo sem jamais ter ouvido falar em sentimento oceânico, consciência cósmica ou a chamada Síndrome de Stendhal. Enquanto um guia de Bari- 
loche recomendava todos a subirem o morro Catedral, para uma incomum apreciação da bela paisagem - algo que me fascina - segui o conselho de um velho senhor que me recomendou subir o Morro Campanário, superior a tudo o que se possa imaginar. Imaginei que fosse ficar naqueles altos por longas horas, mas para surpresa minha, a visão do Morro Campanário era tão sublime que não tive forças para ficar mais do que dois minutos, descendo de imediato por causa desta síndrome. Não deu tempo de tirar uma foto sequer. Era, efetivamente, uma paisagem que roçava o sublime. Da mesma forma que o grande viajante Gurdjev, perambulou meio mundo à procurar de uma razão de ser, ficando alucinado com a dança dos Dervixes, da Turquia, cujo efeito do rodopiar durante meia hora ou mais levava ao mesmo tipo de transe. Santa Tereza de Ávila, uma das cinco Doutoras da Igreja, é considera a maior mística de todos os tempos. Como bem lembrou Gregório de Maragnon, os retratos de sua face lembra muito uma mulher em pleno orgasmo, tal sua sublimação com o eterno, um vazio também conhecido como pequena morte durante nos desligamos do mundo.

O sentimento oceânico pode rebater fortemente no turista como num observador qualquer, quando se vê tomado por tal sensação, mesmo sendo ateu. Assim como na meditação transcendental, que não passa de mera técnica, o sentimento oceânico é experimentado por diversas crenças por nos proporcionar uma visão melhorada do mundo.

Assim, nós, neuróticos urbanos, podemos dar uma guinada realizando outros tipos de viagens, bastando mergulhar a fundo em diversos espaços que não são o do Shopping nem da feijoada de sábado. Espaços de fé, corporativos, filosóficos, transcendentais, romarias, cemitérios, acampamento de refugiados, porque como bem canta Júlio Iglesias, la vida es um soplo.

Em conclusão, o sentimento oceânico não pode ser confundido com as sensações banais que se tem na passagem por lugares banalizados pela coerção dos Tours Operators, que não precisam ser negados, porque algumas condições de alegria e bem estar serão sempre válidos. O que o sentimento oceânico propõe de interessante não se confunde com as impressões banais e passageiras. Ele é uma oportunidade excepcional de termos uma nova visão do mundo, com suas culturas vernaculares, paisagens do dia da criação e possivelmente oportunidade de nossas vidas assumir diferentes rumos, rumos que nos enaltecem, faz nós repensarmos nos nossos valores vitais. Muitas viagens são oportunidades de aprendizados, mas o sentimento oceânico mexe fundo com o que costumamos ignorar.

Nenhuma cirurgia ou poção milagrosa consegue driblar o tempo. Tentemos experimentar o kairós, porque o tempo é um monstro com o qual não se discute. 


\section{BIBLIOGRAFIA}

ALVARENGA, Oneyda. Música popular brasileira. São Paulo, Duas Cidades, 1982

BEAUVOIR, Simone de. Les belles images. Paris: Gallimard, 1966.

BARRERA, José Carlos Bermejo. La consagración de la mentira, 2012

DUNCAN, Isadora. Minha vida. Rio, José Olympio, 1989.

HEIDEGGER, Martin. Sein und Zeit. Ser e Tempo. Unicamp, Petrópolis, 2012 (edição bilíngüe)

HOBSBAWN, Eric A Invenção das tradições. São Paulo: Paz e Terra, 2012

LAQUEUR. The last days of Europe: epitaph for an old continent. New York, Thomas Dunnen, Books, 2097.

LIPOVETSKY, Gilles. A era do Vazio: ensaio sobre o individualismo contemporâneo. Manole, 2005.

LIMA, Rossini Tavares de. "Manifestações folclóricas paulistas", in Ernani da Silva Bruno.

LOBATO, MONTEIRO. Jeca Tatu, in Almanaque do Biotônico Fontoura.

PEREIRA DE QUEIROZ, Maria Isaura Pereira de. Bairros rurais paulistas Dinâmica das relações bairro rural - cidade. São Paulo: Livraria duas Cidades, 1973.

ROJAS, Enrique. Una vidas in valores. Editora Vivir Mejor (Espanha, sem cidade da edição), 1992.

SETTI】, Kilza. Ubatuba no canto de suas praias: estudo do caiçara e de sua produção musical. São Paulo, Ática, 1985. 